\title{
Maternal and fetal outcomes in women undergoing caesarean section under general and spinal anesthesia
}

\author{
Mohamed Ahmed Elkady ${ }^{1}$; Mohammed HussainMostafa ${ }^{1}$; Mahmoud Hasan Mohamed ${ }^{1}$; Hanan \\ Mohammed Ateeyah ${ }^{2}$
}

${ }^{1}$ Faculty of Medicine - Ain Shams University, Professor of Obstetrics \& Gynecology department

${ }^{2}$ M.B.B.Ch, (2007)-AL-Mergeb University

Corresponding: Hanan Mohammed Ateeyah, email: hakeim1980@gmail.com, Tel: +20201120222751

\begin{abstract}
Background: Both spinal and general anaesthesia used for caesarean section have certain advantages and disadvantages and there is no method which is completely ideal. The most important factors for choice of anaesthesia are; pregnant systemic problems and wishes, the urgency of the operation, and the surgeon and the anesthetists experience.

Aim of the Work: These studies aimed at comparing maternal and fetal outcomes in women undergoing elective caesarean section and have spinal anaesthesia with those having general anaesthesia.

Subjects and Methods: This study was carried out at Ain Shams University Maternity Hospital during the period from December 2017 to August 2018 after approval of the hospital health ethical committee. It included 186 patients who had C.S and were subdivided into 2 groups according to a randomization scale. On the day of the operation, each randomly received a closed opaque envelope for the selection of the procedure (spinal versus general).

Results: We noted that the mean haemoglobin and haematocrit values at the 24th hour were higher in the spinal anaesthesia group. The estimated blood loss volume was significantly higher in the general anaesthesia group. The median apgar score at the first and the fifth minutes were significantly higher, and the time that elapsed until the first requirement for analgesia was significantly longer in the spinal anaesthesia group.

Conclusion and Recommendations: General anaesthesia could be thought the quickest anaesthesia method in an emergency since it avoids the possibility of a failed regional block. Meanwhile, it is associated with higher possibility of blood loss and low Apgar score. Thus, using spinal anaesthesia for elective caesarean section is recommended provided that adequate maternal hydration is established and sparing general anaesthesia for emergency caesarean sections or whenever spinal anaesthesia is contraindicated (e.g. coagulopathy, sever thrombocytopenia, anticoagulation or sever degree of malformation of spine).
\end{abstract}

Keywords: Accidental awareness during general anesthesia; combined spinal and epidural; General anesthesia.

\section{INTRODUCTION}

Delivery by caesarean section is by far one of the most commonly performed operations all over the world. Approximately 18.5 million caesarean sections are performed yearly worldwide ${ }^{(1)}$.

About $40 \%$ of the countries have CS rates $<10 \%$, about $10 \%$ have CS rates between 10 and $15 \%$, and approximately $50 \%$ have CS rates $>15 \%$. Countries with CS rates $<10 \%$ account for only $25 \%$ (4.5 millions) of the global CS but for $60 \%$ (77 millions) of the total number births worldwide. On the other hand, $73 \%$ (13.5millions) of the total number of CS are performed in the countries with CS rates $>15 \%$ where $37.5 \%$ (48.4 millions) of the total number of births occur ${ }^{(1)}$.

In Egypt, more than one-half of deliveries in the five-year period before the 2014 were by caesarean section. Caesarean deliveries were more common in the urban areas compared to in rural areas $\left(60 \%\right.$ and $48 \%$ respectively) ${ }^{(2)}$.
When medically justified, caesarean section can effectively prevent maternal and perinatal mortality and morbidity. However, there is no evidence showing the benefits of caesarean delivery for women or infants who do not require the procedure. As with any surgery, caesarean sections are associated with short and long term risk which can extend many years beyond the current delivery and affect the health of the woman, her child and future pregnancies. These risks are higher in woman with limited access to comprehensive obstetric care ${ }^{(3)}$.

This operation requires effective anaesthesia which can be regional (epidural or spinal) or a general anaesthesia. The type of anaesthesia used and the care with which it is administered is an important determine of the outcome of caesarean section ${ }^{(4)}$.

Both spinal and general anaesthesia used for caesarean section have certain advantages and disadvantages and there is no method which is completely ideal. The most important factors for choice of anaesthesia are; pregnant systemic 
problems and wishes, the urgency of the operation, and the surgeon and the anesthetists experience ${ }^{(5)}$.

General anaesthesia refers to the loss of the ability to perceive pain associated with loss of consciousness produced by intravenous or inhalational anaesthetic agents. For caesarean section, this involves the use of thiopentone for induction, tracheal intubation facilitated by suxamethonium, positive-pressure ventilation of the lung with a nitrous oxide/ oxygen mixture plus a volatile agent, and a muscle relaxant ${ }^{(6)}$.

Spinal anaesthesia refers to the use of local anaesthetic solutions to produce circumscribed area of loss of sensation. The spinal anaesthesia used for caesarean section involves the infiltration of a local anaesthetic agent, usually bupivacaine, into the surroundings of the spinal cord through the lower back of the woman (the drug is injected directly into the subarachnoid space) $)^{(6)}$.

Over the last 30 years, the use of spinal anaesthesia is rapidly increasing ${ }^{(7)}$.

Spinal anaesthesia is relatively easy to perform, gives excellent anaesthesia a low potential of toxicity, allows mother to be awake and interact immediately after the birth of the baby. Compared to general anaesthesia it offers less maternal morbidity, comparable less blood loss ${ }^{(8)}$.

It also enables early recovery of gastrointestinal functions, prolonged interval to first analgesic requirement, less analgesic consumption and early ambulation ${ }^{(9)}$.

However, spinal anaesthesia is not free from side effects and has its own complication like maternal hypotension, hypothermia, post-operative headache, accidental total spinal anaesthesia and patients at risk of heavy peripartum haemorrhage may not tolerate the haemodynamic effects of regional anaesthesia ${ }^{(10)}$.

General anaesthesia is a more quickly administered procedure and is often preferred in cases where speed is important ${ }^{(11)}$.

It also used in certain situation like contraindication to regional anaesthesia, failed regional anaesthesia and maternal request ${ }^{(12)}$.

The risks include aspiration of stomach contents, awareness to surgical procedure (due to inadequate anaesthesia), failed intubations, and respiratory problems for both mother and baby ${ }^{(13)}$.

In general, general anaesthesia is preferred for emergency caesarean section since it provides rapid onset of action and more stabilization of the patient's circulation and vital signs, on the other hand regional anaesthesia is preferred for elective operations because of its lower risk of drugs complications to the mother and the fetus ${ }^{(14)}$.

\section{PATIENTS AND METHODS}

\section{Type of study:}

This study was carried out at Ain Shams University Maternity Hospital during the period from December 2017 to August 2018 after approval of the hospital health ethical committee. It included 186 patients who had C.S and were subdivided into 2 groups according to a randomization scale. On the day of the operation each randomly received a closed opaque envelope for the selection of the procedure (spinal versus general). The study was approved by the Ethics Board of Ain Shams University and an informed written consent was taken from each participant in the study.

Inclusion Criteria: Full term. Singleton pregnancy. Maternal age from 20-35. Elective caesarean section.

Exclusion criteria: Multiple pregnancies. Grand multiparity (more than 4 deliveries). Macrosomia (more than or equal 4500 grams). Polyhydramnios (defined as amniotic fluid index more than 25 centimeter). Placental abnormalities such as placental abruption. Preterm rupture of membrane. Preterm delivery (before the $37^{\text {th }}$ weak of pregnancy). Post term delivery (pregnancy exceeding $40^{\text {th }}$ gestational weak). Preeclampsia. Gestational diabetes. Unsuitability for regional anesthesia

Elimination criteria: Refusal to participate after counseling. Any intraoperative complication. Presence of intestinal or omental adhesions. Insertion of intra-peritoneal drain. Excessive small bowel manipulation. The study was prospective, randomized, controlled trial.

Randomization: Computer generated randomization of the two groups (spinal anesthesia and general anesthesia) was done. Before the operation each participant was received a closed opaque envelope for the selection of the procedure. (Spinal versus general).

\section{Methodology:}

Patients were admitted from the outpatient clinic at Ain Shams University Maternity Hospital and were subjected to the following: Counseling about the two types of anesthesia and explanation of the procedure. An 
informed consent to this participation. Full history taking: Full name, age, gravidity and parity. Past medical history of hypertension, DM and other endocrine diseases, also surgical history of abdominal operations. Examination: Vital signs (pulse, temperature, blood pressure and respiratory rate). Measurement of weight $(\mathrm{Kg})$, height (m) to calculate the BMI. Full laboratory investigations especially (CBC, liver and kidney function and RBS). Ultrasound (for assessment of fetal wellbeing). All women fasted at least $6 \mathrm{~h}$ prior to the surgery.

\section{Steps:}

On arrival to the operation room, standard monitoring was applied with noninvasive blood pressure measurement, electro cardiography and pulse oximetry.

\section{General anesthesia:}

Following Diemunsch and Noll ${ }^{(15)}$ parturients in this group received standard rapid sequence induction with pre-oxygenation for 3 minutes followed by $4-5 \mathrm{mg} / \mathrm{kg}$ succinylcholine, cricoid pressure was applied throughout induction once necessary. After correct placement of the tracheal tube was confirmed, anesthesia was maintained with up to $1.5 \%$ isoflurane and oxygen, neuromuscular blockade was maintained with $0.4 \mathrm{mg} / \mathrm{kg}$ atracurium.

\section{Spinal anesthesia:}

Following Armstrong ${ }^{(16)}$, parturients in this group were rehydrated with $500 \mathrm{ml}$ lactated ringer solution intravenously within $15 \mathrm{~min}$ in the sitting position. Low back was prepared and draped in a sterile fashion with betadine solution $10 \%$.

Spinal anesthesia was performed at L2-3 or L3-4 Inter vertebral space using a fine spinal needle (size $22 \mathrm{G} 3.5$ inch). Injection of local anesthetics into the subarachnoid space, Bupivacaine (Marcaine) (1.5-3.5ml) was used.

Operative data: C.S was done by the senior resident according to standard technique demonstrated by Louis et al. ${ }^{(17)}$. The skin was opened with the modified pfannenstiel incision. The anterior abdominal wall was opened in layers. The peritoneum was opened by elevating it with two clamps placed about $2 \mathrm{~cm}$ apart. The peritoneum is incised sharply superiorly to the upper pole of the incision and down warded to just above the peritoneal reflection over the bladder. The lower flap of visceral peritoneum was elevated, and the bladder is gently separated by blunt dissection from the underlying myometrium. The uterus was opened in the lower segment (the lower uterine segment is incised transversely). The baby was delivered: a hand is slipped into the uterine cavity. The head is elevated with the fingers and palm through the incision then the shoulder and baby was delivered. After the shoulders are delivered, an intravenous infusion containing (20 units) of oxytocin per liter of crystalloid is infused at $10 \mathrm{ml} / \mathrm{min}$ until the uterus contracts satisfactorily. The placenta was then delivered by spontaneous delivery, with some cord traction. The uterine incision was then closed with two layers using blunt needle and continuous absorbable suture (Vicryl No.0) intra abdominally. The visceral and parietal peritoneum were closed using continuous absorbable suture (Vicryl No. 0). The recti muscles were approximated with two figure-ofeight sutures of 0 Vicryl. The rectus sheath and subcutaneous tissue was sutured using continuous absorbable suture (Vicryl 1) and the skin was closed by subcuticular suture (Prolene 2.0). The evaluation of the newborn was performed by the pediatrician who was present in the operating room. The apgar scores in the $1^{\text {st }}$ and $5^{\text {th }}$ minutes after the birth were recorded.

After the operation: After the operation all patients were transferred to post-operative room for 6 hours where they were under close observation for vital data, vaginal bleeding and urine output and then transferred to the word until discharge. Both groups had the same hospital fluid regimen which is $500 \mathrm{cc}$ of $5 \%$ glucose every 6 hours, $500 \mathrm{cc}$ of ringer every 12 hours and $500 \mathrm{cc}$ of saline $9 \%$ every 24 hours. All participant received the same intra operative prophylactic antibiotic Amoxicillinetrihydrate +Flucloxacilline monohydrate 1:1 (Flumox) vial 1gm before skin incision that had been repeated every $8 \mathrm{hrs}$ for the first $24 \mathrm{hrs}$ and from the same formula one capsule 500mg tds for one weak was recommended. For postoperative analgesia, intramuscular doses of $75 \mathrm{mg}$ diclofenac sodium (Voltaren, Novartis Pharma, Egypt), a nonsteroidal anti-inflammatory medication, were offered. The first was given once needed after waning of the effect of anesthesia and the second 12 hours later. The time needed for first analgesic request was recorded. Auscultation for intestinal sound was started 2 hours after operation and was performed at one hour interval till normal bowel sounds were detected. Patients were observed if they experienced nausea or not(the patient reported that she had sensation of the need to vomit) at 6 hours intervals after the operation. The presence of vomiting or not was observed and recorded at 6 hours intervals after the operation. The presence of shivering or not was observed and recorded. Patients were asked if they experienced headache attacks. CBC was done 24 hours postoperative. No oral or rectal bowel stimulants were given after surgery. Urinary catheter was removed 6 hours postoperatively and patients were encouraged to ambulate. Eligible criteria for hospital discharge included, stable vital signs with no febrile morbidity for at least 24 hours, ability to 
Maternal and fetal outcomes in women undergoing caesarean section under general ....

ambulate and urinate without assistance, passage of a bowel motion, ability to tolerate solid food without emesis and absence of unresolved other postoperative complications.

\section{Statistical Methods:}

Data were analyzed using MedCalc@ $\odot$ version 18.2.1 (MedCalc@ Software bvba, Ostend, Belgium).

Numerical variables were presented as mean and SD and between-group differences were compared using the unpaired $t$ test.

Categorical variables were presented as number and percentage and differences were compared using Fisher's exact test. Ordinal data were compared using the chi-squared test for trend.

Time to event analysis was done using the Kaplan-Meier method P-values $<0.05$ were considered statistically significant.

\section{RESULTS}

The current study was conducted on 186 pregnant women at Ain Shams University Maternity Hospital from December 2017 to August 2018 to compare the maternal and fetal outcomes after general versus spinal anaesthesia in caesarean section.

Demographic data of the patients participated in the study as shown in the next table (1).

Table (1): Demographic characteristics of patients in both groups.

\begin{tabular}{|l|l|c|c|c|c|c|c|}
\hline \multirow{2}{*}{ Variable } & \multicolumn{2}{|c|}{$\begin{array}{c}\text { Spinal } \\
\text { anesthesia } \\
(\mathbf{n = 9 3})\end{array}$} & \multicolumn{2}{|c|}{$\begin{array}{c}\text { General } \\
\text { anesthesia } \\
(\mathbf{n = 9 3})\end{array}$} & Difference & 95\% CI & P-value* \\
\cline { 2 - 5 } & Mean & SD & Mean & SD & & & \\
\hline Age (years) & 28.5 & 4.7 & 27.8 & 5.3 & -0.7 & -2.1 to 0.7 & 0.341 \\
\hline BMI $\left(\mathrm{kg} / \mathrm{m}^{2}\right)$ & 26.8 & 1.8 & 26.7 & 1.6 & -0.1 & -0.6 to 0.4 & 0.651 \\
\hline
\end{tabular}

Data are mean and standard deviation (SD).

$95 \% \mathrm{CI}=95 \%$ confidence interval.

*Unpaired t test.

There were no significant differences between women of both groups regarding age and body mass index.

Table (2): Obstetric history of patients in both groups.

\begin{tabular}{|c|c|c|c|c|c|c|}
\hline \multirow[t]{2}{*}{ Parity } & \multicolumn{2}{|c|}{$\begin{array}{c}\text { Spinal anesthesia } \\
(\mathrm{n}=93)\end{array}$} & \multicolumn{2}{|c|}{$\begin{array}{c}\text { General anesthesia } \\
(n=93)\end{array}$} & \multirow[t]{2}{*}{$\chi^{2}(\mathrm{df}=1)$} & \multirow[t]{2}{*}{ P-value* } \\
\hline & $\mathbf{N}$ & $\%$ & $n$ & $\%$ & & \\
\hline PG & 16 & $17.2 \%$ & 26 & $28.0 \%$ & \multirow{4}{*}{1.842} & \multirow{4}{*}{0.175} \\
\hline P1 & 22 & $23.7 \%$ & 19 & $20.4 \%$ & & \\
\hline $\mathrm{P} 2$ & 25 & $26.9 \%$ & 22 & $23.7 \%$ & & \\
\hline P3 & 30 & $32.3 \%$ & 26 & $28.0 \%$ & & \\
\hline
\end{tabular}

Data are number (n) and percentage (\%).

$\chi 2=$ chi-squared s statistic, $\mathrm{df}=$ degree of freedom.

*Chi-squared test for trend.
Table (2) illustrates that there is no statistically significant difference between study groups regarding the parity.

Table (3): Indication for CS in both study groups.

\begin{tabular}{|c|c|c|c|c|c|}
\hline \multirow[t]{2}{*}{$\begin{array}{c}\text { Indication for } \\
\text { CS }\end{array}$} & \multicolumn{2}{|c|}{$\begin{array}{c}\text { Spinal } \\
\text { anesthesia } \\
(\mathbf{n}=93)\end{array}$} & \multicolumn{2}{|c|}{$\begin{array}{c}\text { General } \\
\text { anesthesia } \\
(\mathbf{n}=93)\end{array}$} & \multirow[t]{2}{*}{ P-value* } \\
\hline & $\mathbf{N}$ & $\%$ & $\mathbf{N}$ & $\%$ & \\
\hline Previous CS & 44 & $47.3 \%$ & 41 & $44.1 \%$ & \multirow{7}{*}{0.289} \\
\hline $\begin{array}{l}\text { Obstructed } \\
\text { labor }\end{array}$ & 13 & $14.0 \%$ & 9 & $9.7 \%$ & \\
\hline Failed progress & 9 & $9.7 \%$ & 21 & $22.6 \%$ & \\
\hline $\begin{array}{l}\text { Breech } \\
\text { presentation }\end{array}$ & 14 & $15.1 \%$ & 9 & $9.7 \%$ & \\
\hline Transverse lie & 1 & $1.1 \%$ & 3 & $3.2 \%$ & \\
\hline Infertility & 7 & $7.5 \%$ & 6 & $6.5 \%$ & \\
\hline Cardiac disease & 3 & $3.2 \%$ & 2 & $2.2 \%$ & \\
\hline $\begin{array}{l}\text { Previous } \\
\text { cervical repair }\end{array}$ & 2 & $2.2 \%$ & 1 & $1.1 \%$ & \\
\hline Epilepsy & 0 & $.0 \%$ & 1 & $1.1 \%$ & \\
\hline
\end{tabular}

Data are number (n) and percentage (\%).

*Fisher's exact test.

Table (3) illustrates that there is no statistically significant difference between study groups as regards to the indication of caesarean section.

Table (4): Maternal outcomes in both study groups.

\begin{tabular}{|c|c|c|c|c|c|c|c|}
\hline \multirow[t]{2}{*}{ Variable } & \multicolumn{2}{|c|}{$\begin{array}{c}\begin{array}{c}\text { Spinal } \\
\text { anesthesia } \\
(\mathbf{n}=93)\end{array} \\
\end{array}$} & \multicolumn{2}{|c|}{$\begin{array}{c}\text { General } \\
\text { anesthesia } \\
(\mathbf{n}=93)\end{array}$} & \multirow{2}{*}{$\begin{array}{c}\text { Differenc } \\
\mathrm{e}\end{array}$} & \multirow{2}{*}{$\begin{array}{c}95 \% \mathrm{C} \\
\mathrm{I}\end{array}$} & \multirow{2}{*}{$\begin{array}{c}\text { P- } \\
\text { value* }\end{array}$} \\
\hline & $\begin{array}{c}\text { Mea } \\
n\end{array}$ & SD & $\begin{array}{c}\text { Mea } \\
\text { n }\end{array}$ & SD & & & \\
\hline $\begin{array}{l}\text { Postoperative } \\
\text { hemoglobin }(\mathrm{g} / \mathrm{dl})\end{array}$ & 10.4 & 1.1 & 9.4 & 1.5 & -0.9 & \begin{tabular}{|c|}
-1.4 to - \\
0.6
\end{tabular} & $\begin{array}{c}<0.000 \\
1\end{array}$ \\
\hline $\begin{array}{l}\text { Absolute } \\
\text { Hemoglobin drop }(\mathrm{g} / \mathrm{dl} \\
\end{array}$ & 0.91 & 0.66 & 1.29 & 0.95 & 0.38 & $\begin{array}{c}0.1 \text { to } \\
0.6\end{array}$ & 0.002 \\
\hline $\begin{array}{l}\text { Postoperative } \\
\text { hematocrit }(\%)\end{array}$ & 32.2 & 3.2 & 30.1 & 4.0 & -2.0 & \begin{tabular}{|c|}
-3.1 to - \\
1.0
\end{tabular} & $<0.001$ \\
\hline $\begin{array}{l}\text { Absolute Hematocrit } \\
\text { drop (\%) }\end{array}$ & 2.9 & 1.9 & 3.4 & 2.8 & 0.5 & $\begin{array}{c}-0.2 \text { to } \\
1.2\end{array}$ & 0.133 \\
\hline $\operatorname{EBL}(\mathrm{ml})$ & 411.6 & $\begin{array}{c}100 . \\
3\end{array}$ & 501.2 & 119.7 & 89.5 & $\begin{array}{l}6.3 \text { to } \\
172.8\end{array}$ & 0.035 \\
\hline TFA request (min) & 2.4 & 1.8 & 1.7 & 1.2 & 0.7 & $\begin{array}{c}0.3 \text { to } \\
1.1\end{array}$ & 0.002 \\
\hline $\begin{array}{l}\text { Time to recover } \\
\text { intestinal sounds (h) }\end{array}$ & 6.0 & 1.3 & 7.1 & 1.5 & 1.1 & $\begin{array}{l}0.7 \text { to } \\
1.5\end{array}$ & $\begin{array}{c}<0.000 \\
1\end{array}$ \\
\hline
\end{tabular}

Data are mean and standard deviation $(\mathrm{SD}) ; 95 \% \mathrm{CI}=95 \%$ confidence interval.

*Unpaired t test.

Table (4) displays that there is statistically significant differences with p- value $(<0.0001)$ between study groups as regards to the 
postoperative hemoglobin with high mean among spinal anesthesia group.

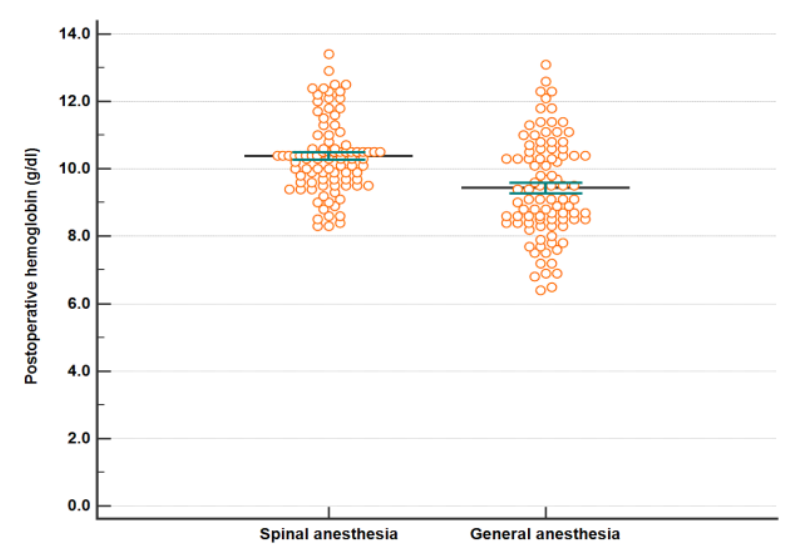

Fig (1): Postoperative hemoglobin in both study groups. Horizontal line (black) represents the mean. Error bars (green) represent the standard error (SE). Markers represent individual observations.

Table (4) reveals that there is statistically significant difference with p-value $(0.002)$ between study groups as regards the absolute hemoglobin drop $(\mathrm{g} / \mathrm{dl})$ with high mean among general anesthesia group.

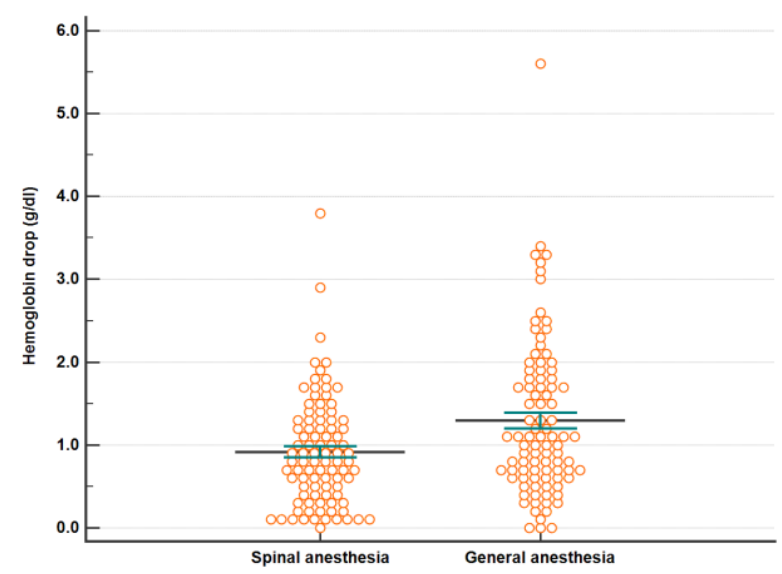

Fig (2): Drop in hemoglobin in both study groups. Horizontal line (black) represents the mean. Error bars (green) represent the standard error (SE). Markers represent individual observations

Table (4) demonstrates that there is statistically significant difference with $\mathrm{p}$-value (0.001) between study groups as regards to the postoperative haematocrit with high mean among spinal anesthesia group.

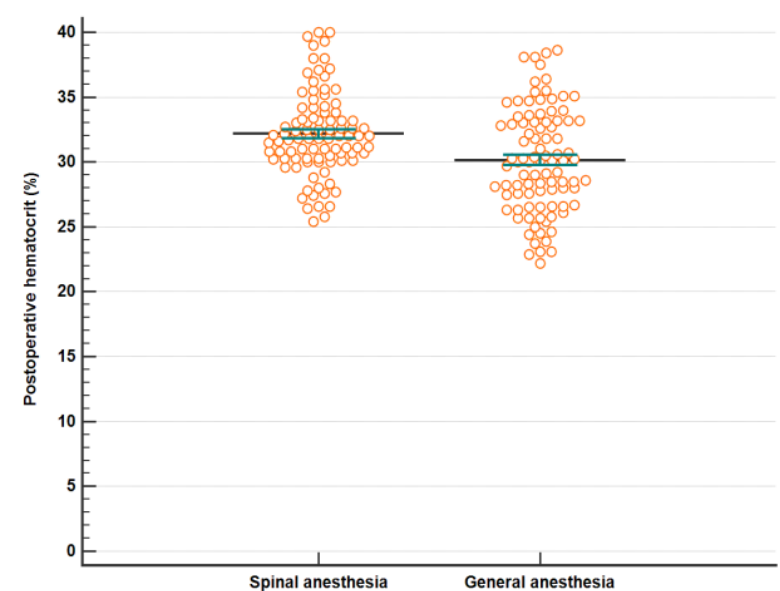

Fig (3): Postoperative hematocrit in both study groups. Horizontal line (black) represents the mean. Error bars (green) represent the standard error (SE). Markers represent individual observations

Table (4) shows that there is no statistically significant difference with $p$-value $(0.133)$ between study group as regards to the absolute haematocrit drop values $(\%)$.

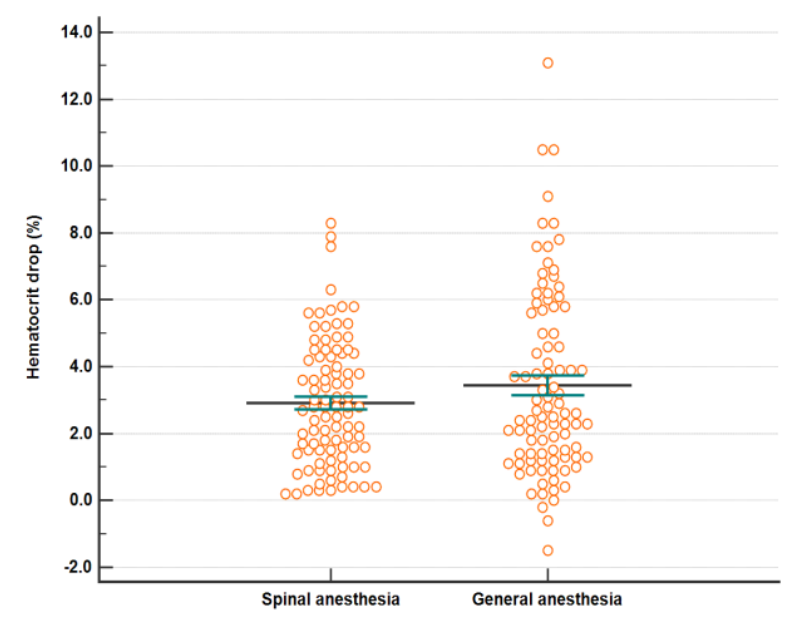

Fig (4): Drop in hematocrit in both study groups. Horizontal line (black) represents the mean. Error bars (green) represent the standard error (SE). Markers represent individual observations.

Table (4) illustrates that there is a statistically significant difference with $p$ value $(0.035)$ between study groups as regards to the estimated blood loss ( $\mathrm{ml})$ with high mean among general anesthesia group. 


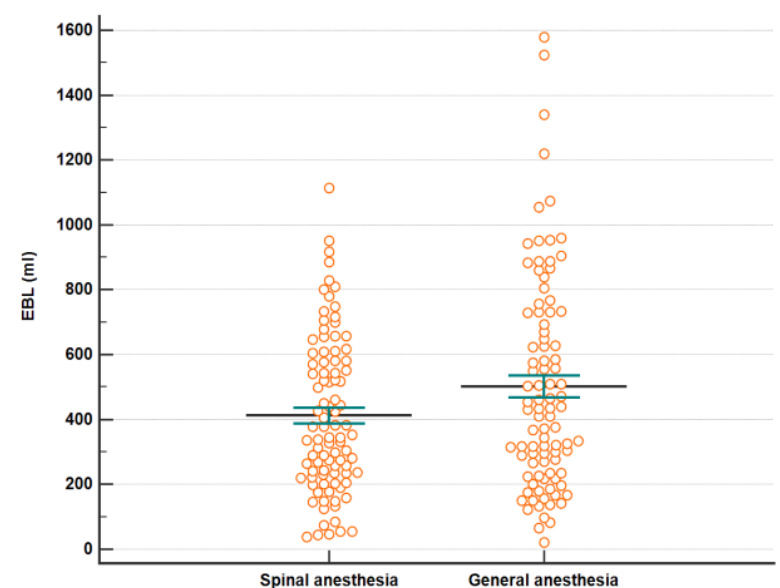

Fig (5): EBL in both study groups. Horizontal line (black) represents the mean. Error bars (green) represent the standard error (SE). Markers represent individual observations.

Table (4) manifests that there is statistically significant difference with $\mathrm{p}$-value (0.002) between study groups as regards to the first analgesic request (hr) with high mean among spinal anesthesia group.

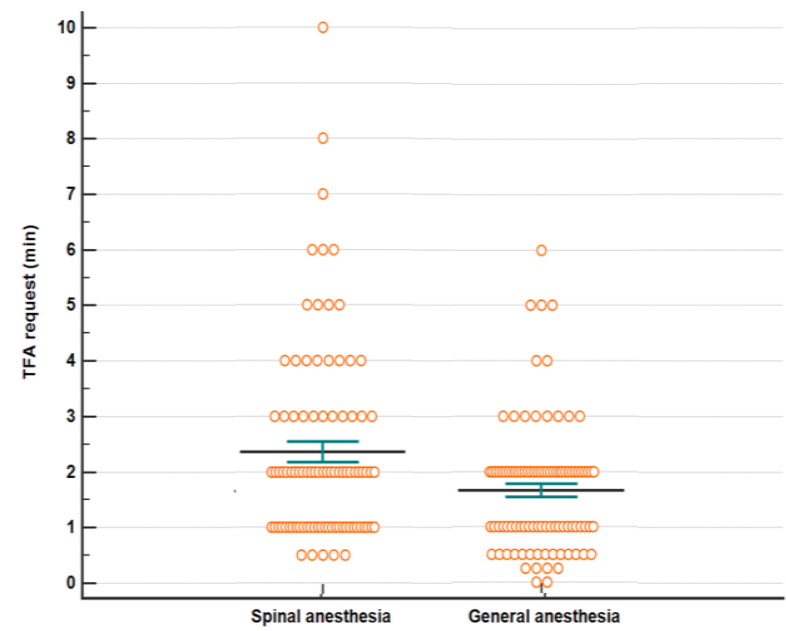

Fig (6): TFA request in both study groups. Horizontal line (black) represents the mean. Error bars (green) represent the standard error (SE). Markers represent individual observations.

Table (4) establishes that there is statistically significant difference with p-value (0.0001) between study groups as regards to the first intestinal sound (hr) with high mean among general anesthesia group.

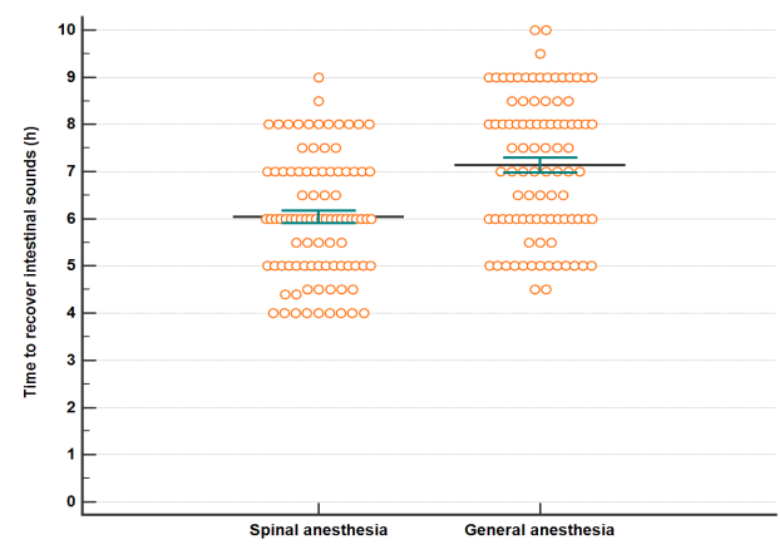

Fig (7): Time to recover intestinal sounds in both study groups. Horizontal line (black) represents the mean. Error bars (green) represent the standard error (SE). Markers represent individual observations.

Table (5): Fetal outcomes in both study groups.

\begin{tabular}{|c|c|c|c|c|c|c|c|}
\hline \multirow{2}{*}{ Variable } & \multicolumn{2}{|c|}{$\begin{array}{c}\text { Spinal } \\
\text { anesthesia } \\
\text { (n=93) }\end{array}$} & \multicolumn{2}{|c|}{$\begin{array}{c}\text { General } \\
\text { anesthesia } \\
\text { (n=93) }\end{array}$} & Difference & 95\% CI & $\begin{array}{c}\text { P- } \\
\text { value** }\end{array}$ \\
\cline { 2 - 5 } & Mean & SD & Mean & SD & & & \\
\hline Apgar 1 & 6.8 & 1.3 & 6.0 & 1.6 & -0.8 & -1.2 to -0.4 & $<0.001$ \\
\hline Apgar 5 & 8.6 & 0.6 & 8.3 & 1.2 & -0.4 & -0.6 to -0.1 & 0.010 \\
\hline
\end{tabular}

Data are mean and standard deviation (SD). $95 \% \mathrm{CI}=95 \%$ confidence interval.

*Unpaired t test.

Table (5) expresses that there is statistically significant difference between study group as regards to apgar score at 1 minute $(p<0.001)$ and apgar score at 5 minute $(p=0.010)$ with high mean among spinal anesthesia group.

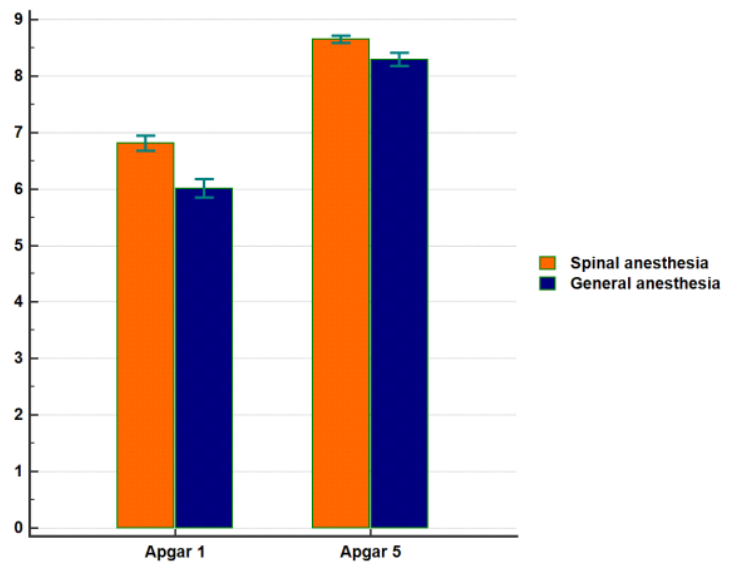

Fig (8): Apgar score at 1 minute and 5 minutes in both study groups.

Horizontal line (black) represents the mean. Error bars (green) represent the standard error (SE). Markers represent individual observations. 
Table (6): Incidence of maternal and fetal adverse outcomes in both study groups

\begin{tabular}{|l|c|c|c|c|c|c|}
\hline \multirow{2}{*}{$\begin{array}{c}\text { Adverse } \\
\text { outcome }\end{array}$} & \multicolumn{2}{|c|}{$\begin{array}{c}\text { Spinal anesthesia } \\
(\mathbf{n = 9 3})\end{array}$} & \multicolumn{2}{c|}{$\begin{array}{c}\text { General anesthesia } \\
(\mathbf{n = 9 3}\end{array}$} & \multirow{2}{*}{$\boldsymbol{\chi 2}(\mathbf{d f =}=\mathbf{1 )}$} & \multirow{2}{*}{ P-value* } \\
\cline { 2 - 5 } & $\mathbf{N}$ & $\boldsymbol{\%}$ & $\mathbf{n}$ & $\mathbf{\%}$ & & \\
\hline Low Apgar 1 & 31 & $33 \%$ & 53 & $57 \%$ & 10.507 & 0.001 \\
\hline Low Apgar 5 & 1 & $1.1 \%$ & 2 & $2.2 \%$ & - & $1.000 \#$ \\
\hline Nausea & 8 & $8.6 \%$ & 13 & $14.0 \%$ & 1.342 & 0.247 \\
\hline Vomiting & 2 & $2.2 \%$ & 1 & $1.1 \%$ & - & $1.000 \#$ \\
\hline Headache & 23 & $24.7 \%$ & 14 & $15.1 \%$ & 2.733 & 0.098 \\
\hline Shivering & 44 & $47.3 \%$ & 29 & $31.2 \%$ & 5.073 & 0.024 \\
\hline $\begin{array}{l}\text { Pain requiring } \\
\text { analgesic }\end{array}$ & 91 & $97.8 \%$ & 93 & $100 \%$ & - & $0.497 \#$ \\
\hline
\end{tabular}

Data are number (n) and percentage (\%).

$\chi 2=$ chi-squared statistic, $\mathrm{df}=$ degree of freedom

*Pearson Chi-squared test unless otherwise indicated.

\#Fisher's exact test.

Table (6) illustrates that there is statistically significant difference with p-value (0.001) as regards to incidence of low apgar score at 1 minute with high mean among general anesthesia group.

Table (6) indicates that there is statistically significant difference between both group with p- value (0.024) as regards to the incidence of shivering with high mean among spinal anesthesia group, whereas there is no statistical difference regarding the incidence of nausea $(p=0.247)$, vomiting $(p=1.000)$, headache $(\mathrm{p}=0.098)$ and pain requiring analgesic $(\mathrm{p}=0.497)$.

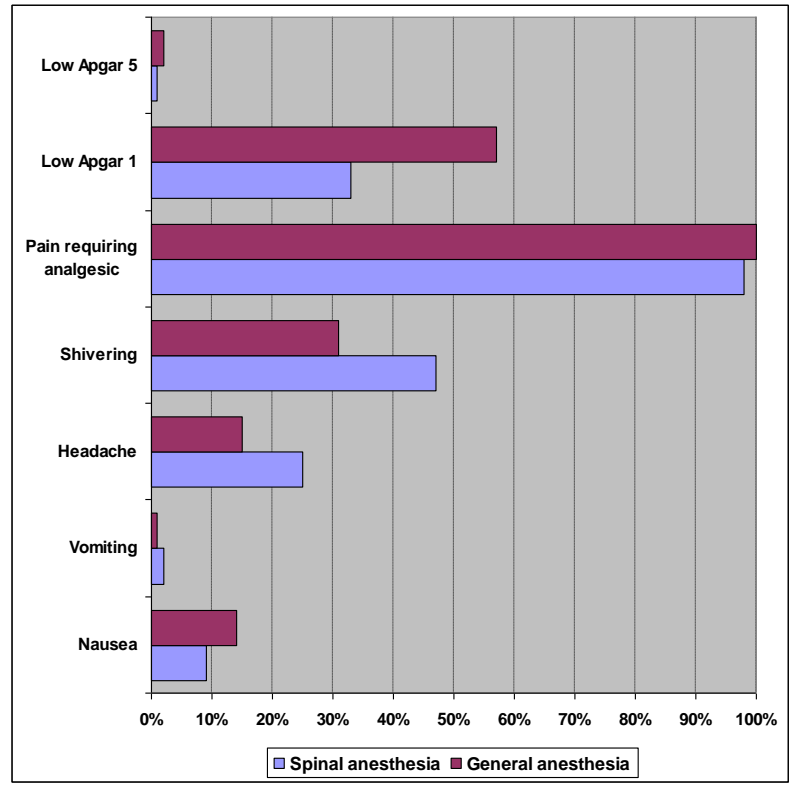

Fig (9): Incidence of maternal and fetal adverse outcomes in both study groups.
Table (7): Risk analysis for the Incidence of adverse outcomes in both study groups.

\begin{tabular}{|l|c|c|c|c|c|c|}
\hline Outcome & RR & $\mathbf{9 5 \%} \mathbf{C I}$ & $\mathbf{Z}$ & $\mathbf{P}$-value & $\begin{array}{c}\text { NNT } \\
\text { NNH }\end{array}$ & $\mathbf{9 5 \% \text { CI }}$ \\
\hline $\begin{array}{l}\text { Low } \\
\text { Apgar 1 }\end{array}$ & 0.58 & $\begin{array}{c}0.42 \text { to } \\
0.82\end{array}$ & $\begin{array}{c}3.1 \\
16\end{array}$ & 0.002 & 4.2 & $\begin{array}{c}2.7 \text { (Benefit) to } \\
10.2 \text { (Benefit) }\end{array}$ \\
\hline $\begin{array}{l}\text { Low } \\
\text { Apgar 5 }\end{array}$ & 0.50 & $\begin{array}{c}0.05 \text { to } \\
5.42\end{array}$ & $\begin{array}{c}0.5 \\
70\end{array}$ & 0.569 & 93.0 & $\begin{array}{c}39.3 \text { (Harm) to } \\
21.3 \text { (Benefit) }\end{array}$ \\
\hline Nausea & 0.62 & $\begin{array}{c}0.27 \text { to } \\
1.41\end{array}$ & $\begin{array}{c}1.1 \\
43\end{array}$ & 0.253 & 18.6 & $\begin{array}{c}27.1 \text { (Harm) to } 6.9 \\
\text { (Benefit) }\end{array}$ \\
\hline Vomiting & 2.00 & $\begin{array}{c}0.18 \text { to } \\
21.68\end{array}$ & $\begin{array}{c}0.5 \\
70\end{array}$ & 0.569 & $93.0 *$ & $\begin{array}{c}21.3 \text { (Harm) to } \\
39.3 \text { (Benefit) }\end{array}$ \\
\hline Headache & 1.64 & $\begin{array}{c}0.90 \text { to } \\
2.99\end{array}$ & $\begin{array}{c}1.6 \\
24\end{array}$ & 0.104 & $10.3 *$ & $\begin{array}{c}4.7 \text { (Harm) to 58.4 } \\
\text { (Benefit) }\end{array}$ \\
\hline Shivering & 1.52 & $\begin{array}{c}1.05 \text { to } \\
2.20\end{array}$ & $\begin{array}{c}2.2 \\
06\end{array}$ & 0.027 & $6.2 *$ & $\begin{array}{c}43.7 \text { (Harm) to 3.3 } \\
\text { (Harm) }\end{array}$ \\
\hline $\begin{array}{l}\text { Pain } \\
\text { requiring } \\
\text { analgesic }\end{array}$ & 0.98 & $\begin{array}{c}0.95 \text { to } \\
1.01\end{array}$ & $\begin{array}{c}1.4 \\
14\end{array}$ & 0.157 & $46.5 *$ & $\begin{array}{c}19.6 \text { (Benefit) to } \\
125.4 \text { (Harm) }\end{array}$ \\
\hline
\end{tabular}

$\mathrm{RR}=$ relative risk, $95 \% \mathrm{CI}=95 \%$ confidence interval, $\mathrm{Z}$ $=\mathrm{z}$-statistic, $\mathrm{NNT}=$ number needed to treat (or to benefit), $\mathrm{NNH}=$ number needed to harm. ${ }^{*} \mathrm{NNH}$.

Table (7): illustrates that spinal anesthesia is associated with significantly lower risk for low (<7) Apgar score at 1 minute $(\mathrm{RR}=0.58,95 \% \mathrm{CI}$ $=0.42-0.82, \mathrm{P}=0.002)$, but it is associated with significantly higher risk for shivering $(R R=1.52$, $95 \% \mathrm{CI}=1.05-2.20, \mathrm{P}=0.027$ ).

\section{DISCUSSION}

Delivery by caesarean section is by far one of the most commonly performed operations all over the world. Approximately 18.5 million caesarean sections are performed yearly worldwide ${ }^{(1)}$.

This operation requires effective anaesthesia which can be regional (epidural or spinal) or a general anaesthesia. The type of anaesthesia used and the care with which it is administered is an important determinant of the outcome of caesarean section ${ }^{(4)}$.

Both spinal and general anaesthesia used for caesarean section have certain advantages and disadvantages and there is no method which is completely ideal. The most important factors for choice of anaesthesia are: systemic problems, the urgency of the operation, the surgeon and the anaesthetists experience and wishes ${ }^{(5)}$.

This prospective randomized controlled study compared between general and spinal anaesthesia regarding the maternal and fetal outcomes after caesarean section. 
In this study there was no demographic difference between women in both groups regarding the mean age, BMI, parity and indication of caesarean section $(\mathrm{p}>0.05)$.

Also there was no significant difference between both groups as regard to preoperative blood pressure, heart rate and temperature $(\mathrm{p}>0.05)$.

This study showed non significant difference between both groups as regard to preoperative haemoglobin levels as $\mathrm{p}=0.586$; the mean preoperative haemoglobin levels was $11.3 \pm 1.2 \mathrm{~g} / \mathrm{dl}$ in spinal anaesthesia group vs. $11.2 \pm 1.3 \mathrm{~g} / \mathrm{dl}$ in general anaesthesia group.

As regard to the postoperative haemoglobin there was a significant difference between both groups $(p<0.0001)$, there was less reduction in haemoglobin level in spinal group than general group (the mean postoperative haemoglobin level was $10.4 \pm 1.1 \mathrm{~g} / \mathrm{dl}$ vs. $9.4 \pm 1.5 \mathrm{~g} / \mathrm{dl}$ respectively). There was also a significant difference between both groups as regard to the absolute drop in haemoglobin $(\mathrm{g} / \mathrm{dl})$ as $\mathrm{p} 0.002$, there was less drop in spinal group compared to the general group (the mean absolute drop in haemoglobin level was $0.91 \pm 0.66 \mathrm{~g} / \mathrm{dl}$ vs. $1.29 \pm 0.95 \mathrm{~g} / \mathrm{dl}$ respectively).

In this study, there was no significant difference between both groups as regard preoperative haematocrit values $(\mathrm{p}=0.352)$, the mean preoperative haematocrit values were $35.1 \pm 3.5 \%$ in spinal group vs. $34.6 \pm 3.8 \%$ in the general group.

As regard to the postoperative haematocrit values, there were significant differences between both groups $(p<0.001)$; there was less drop in haematocrit values in spinal anaesthesia group than general anaesthesia group (the mean haematocrit values was $32 \pm 3.2 \%$ vs. $30.1 \pm 4$ respectively). There was no significant difference between both groups as regard to the absolute drop in haematocrit values $(\%)$ as $\mathrm{p}=0.133$.

The results of the present study goes with those of the previous study conducted by Ezzatalsadat et al. ${ }^{(18)}$ which showed that mean loss of haemoglobin in spinal group was significantly lower than in general group $(p=0.017)$. Mean loss of haematocrit in spinal group was significantly lower than in general group $(\mathrm{p}=0.035)$.

Another study conducted by Marzouni et $\boldsymbol{a l} .{ }^{(19)}$ showed that the amount of decrease in haemoglobin and haematocrit level after caesarean section in parturients who were undergoing general anaesthesia, significantly higher than those who were undergoing spinal anaesthesia. According to the result of this study, the amount of decrease in haemoglobin and haematocrit in the general anaesthesia group was $0.8 \pm 0.03 \mathrm{~g} / \mathrm{dl}$ and $4.4 \pm 2.2 \%$ and the amount of decrease in the spinal anaesthesia group $0.67 \pm 0.1$ $\mathrm{g} / \mathrm{dl}$ and $4 \pm 0.6 \%(\mathrm{p}=0.002$ and $\mathrm{CI}=95 \%)$.

Regarding to the amount of estimated blood loss, a statistical significance between the two groups was found $(\mathrm{p}=0.035)$ in which spinal anaesthesia group had less estimated blood loss than general anaesthesia group. The amount of estimated blood loss in spinal group declared a mean value of $411.6 \pm 238.3 \mathrm{ml}$ vs. $501 \pm 329.7 \mathrm{ml}$ in general anaesthesia group.

This conclusion agrees with the result of Jeong et al. ${ }^{(20)}$ who showed that women underwent caesarean section under spinal anaesthesia had lost blood less than those under general anaesthesia $(1.160 \pm 710 \mathrm{ml}$ vs. $1.230 \pm 650 \mathrm{ml}$ respectively).

This study showed that the parturient who received spinal anaesthesia had a significant longer time interval to first analgesic request. The mean time interval for the first analgesic request was longer in spinal group than general group $(2.4 \pm 1.8$ hours vs $1.7 \pm 1.2$ respectively). There was a significant difference $(\mathrm{p}=0.002)$.

The results of the present study confirm those found in previous randomized controlled trial conducted by Lada and Adriana ${ }^{(21)}$ who stated that the time till first request for postoperative analgesia was longer with spinal anaesthesia than general anaesthesia as the mean time till first analgesic request with spinal anaesthesia group $(n=35)$ was 159 
minutes while with general anaesthesia group was 119 minutes.

This study showed that there was statistically significant effect of spinal anaesthesia versus general anaesthesia in term of shorter mean time interval to normal intestinal sound ( $6 \pm 1.3$ vs. $7.1 \pm 1.5$ hours). This agrees with the result of Saygi et al. ${ }^{(22)}$ study which included a total of 100 patients divided into two groups of 50 each, named the general anaesthesia and spinal anaesthesia groups, according to the route of administration of anaesthesia. The study revealed that the starting time for bowel sounds $(22.08 \pm 7.48$ vs. $18.75 \pm 9.2 ; \mathrm{p}=0.049$ ) were significantly longer in the general anaesthesia group compared to that in the spinal anaesthesia group.

In this study, there was no significant difference between both groups as regard to the incidence of postoperative nausea $(p=0.247)$. However, it was slightly more frequent in general group than spinal group (14\% vs. $8.6 \%$ respectively).

As regard to the incidence of postoperative vomiting, this study showed no significant difference between both groups $(\mathrm{p}=1.000)$.

In this study, there was no significant difference between both groups as regard to the incidence of postoperative headache $(p=0.098)$. However, it was slightly more frequent in the spinal group than general group ( $24.7 \%$ vs $15.1 \%$ respectively).

As regard to the incidence of postoperative shivering, it was more frequent in spinal group than general group ( $47.3 \%$ vs. $31.2 \%$ respectively) with significant difference $(\mathrm{p}=0.024)$.

A prospective observational study done by Luggya et al. $^{(23)}$ showed that 22 out of 270 patients undergoing caesarean section under spinal anaesthesia developed postoperative shivering giving prevalence of $8.15 \%$ with intraoperative hypotension and hypothermia as main associated factors. This study noted that postoperative shivering can be effectively controlled by $25 \mathrm{mg}$ intravenous pethedine.

In this study there was statistically significant difference between the study groups as regards the mean of Apgar score at 1 minute $(6.8 \pm 1.3$ in the spinal group vs. $6 \pm 1.2$ in the general group $(\mathrm{P}<0.001)$ and significant difference between them as regards the mean of Apgar score at 5 minute $(8.6 \pm 0.6$ in spinal group vs. $8.3 \pm 1.2$ in general group. $\mathrm{P}=0.01$ ).

This conclusion agrees with that of Mekonnen and Deska ${ }^{(24)}$ who stated that the first and fifth Apgar score were better in neonates delivered under spinal anaesthesia as compared to general anaesthesia.

The present work also agrees that done by Hogan et al. ${ }^{(25)}$ which showed that there significantly increased risks of low apgar score if the delivery was performed under general anaesthesia rather than spinal anaesthesia.

\section{REFERENCES}

1. WHO (2010): The Global Numbers and costs of Additionally Needed and Unnecessary Caesarean Section Performed per Year: Overuse as a Barrier to Universal Coverage. In: Gibbons L, Belizan JM, Lauer JA. World Health Report Background Paper, 30:7.

2. El-Zanaty E (2014): Egypt Demographic and Health Survey September 2014. Rockville, Maryland: Ministry of Health and Population. Available at: https:// dhsprogram. com/ pubs/ pdf/ FR302/ FR302. pdf. Last accessed June 2018.

3. Lumbiganon P, Laopaiboon M, Gulmezoglu AM et al. (2010): Method of delivery and pregnancy outcomes in Asia: the WHO global survey on maternal and perinatal health 2007-08. Lancet, 375:490-9.

4. Anderson F, Auster H, Marx F et al. (1987): Neonatal status in relation to incision intervals, obstetric factors and anaesthesia at caesarean delivery. American journal of perinatology, 4:279-83.

5. Wu CL (2006): Analysis on doula parturition method in clinical practice field. Henan J Prev Med., 2006:05.

6. Thorburn J (1998): Obstetric anaesthesia and analgesia. In: Aitkenhead AR, Smith G editor(s). Textbook of anaesthesia. $3^{\text {rd }}$ Edition. London: Churchill Livingstone.

7. Ashok J (2010): Complication of regional and general anaesthesia in obstetric practice. Indian J Anesth., 54(5):415-420. 
8. Danelli G, Fenalli G, Berti M et al. (2009): Spinal roprivacaine or bupivacaine for caesarean delivery; A prospective randomized double blind comparison. Regional anaesthesia and pain medicine,29:221-26.

9. Havas F, Orhansungur M, Yenigun Y et al. (2013): Spinal anaesthesia for elective caesarean section is associated with shorter hospital stay compared to general anaesthesia. Agri.,25(2):55-63.

10. Jenkins JG and Khan MM (2003): Anaesthesia for caesarean section delivery. Rev ColombAnestesiol., 6(3):40:203.

11. Enkin M, Keirse MJ, Neilson J, Crowther C, Duley L, Hodnett E, Hofmeyr GJ (2001): Effective care in pregnancy and childbirth: a synopsis. Birth, 28(1):41-51.

12. Afolabi BB, Lesi FEA and Merah NA (2010): Regional versus general anaesthesia for caesarean section. Cochrane Database of Systemic Reviews, 1:10(1):51-5.

13. Afolabi B, Kaka A and Abudu O (2003): Spinal and general anaesthesia for emergency caesarean section: effects on neonatal Apgar score and maternal haematocrit. Niger Postgrad Med J., 10(1):51-5.

14. Almomany $O$ (2012): Effect of general anaesthesia compared to regional anaesthesia on the Apgar score of neonates. Sudan JMS., 7(3): 179-182.

15. Diemunsch $P$ and Noll $E$ (2017): General anesthesia for caesarean section. In: Capogna G (eds) Anesthesia for Caesarean Section. Springer.

16. Armstrong S (2017): Spinal Anesthesia for Caesarean Section G. Capogna (ed), Anesthesia for Caesarean Section, Springer International Publishing Switzerland; ch4, pp. 69-64

17. Louis HS, Isaacs, $C$, Pritzker JG et al. (2016): Caesarean Delivery Medscape Medical News. Available at http:// emedicine. Medscape.

18. Ezzatalsadat J, Shamsi N, Aamir J et al. (2012): Comparison of hematocrit concentration after caesarean section between two methods: general anesthesia Vs spinal anesthesia. Life Science Journal, 9(4):1258-60.
19. Marzouni HZ, Lavasani Z, Riahi S et al. (2014): A Comparative Study about the Effect of General Anesthesia and Spinal Anesthesia on changes in Blood Parameters after Caesarean Section in Doctor Ganjavian Hospital in Dezfool City in 2013. International Journal of Advanced Research, 2(8): 774-779.

20. Jeong K, Hyang L, Eun $K$ et al.(2012): The effect of type of anaesthesia on intra and postoperative blood loss at elective caesarean section. Korean Journal of anesthesiol., 62(2): 125-129.

21. Lada $K$ and Adriana M (2009): Effect of general anesthesia versus spinal anesthesia for caesarean section on post-operative analgesic consumption and postoperative pain. Periodicum Biologorum., 3(2)251-255.

22. Saygi AI, Ozdamar O, Gun I et al. (2015): Comparison of maternal and fetal $b$ outcomes among patients undergoing caesarean section under general and spinal anesthesia:a randomized clinical trial. Sao Paulo Med J., 133:227-234.

23. Luggya TS, Kabuye RN, Mijumbi $\mathrm{C}$ et al. (2016): Prevalence, associated factors and treatment of post spinal shivering in a sub-saharan tertiary hospital: a prospective observational study. BMC anesthesiology, 16(1):100.

24. Mekonnen S and Deska K (2016): Effect of type of anaesthesia on neurobehavioral response and Apgar score in neonates delivered with caesarean section in Dilla University Referral Hospital. J Anesth Clin Res., DOI:10.4172/2155-6148.1000642.

25. Hogan ML, Ingemarsson I, ThorngrenJerneck K $\boldsymbol{e t}$ al. (2007): How often is a low 5- min Apgar score in term neoborns due to asphyxia? Eur J Obstet Gynecol Reprod Biol., 130:169-175. 